\title{
SERVICE QUALITY EVALUATION OF INTERNATIONAL LOGISTICS COMPANY: AN EMPIRICAL CASE USING QFD APPROACH
}

Sheng Teng Huang*, EmrahBulut**, OkanDuru*** and ShigeruYoshida****

\begin{abstract}
The national logistics policy report published by Ministry of Land, Infrastructure and Tourism in 2011 proposes to establish international logistics strategy teams in 10 different regions around Japan to satisfy the increasing demand for advance transportation infrastructure and stay competitive in Asia Pacific. The globalization of world economies creates many opportunities as well as challenges for international logistics companies to gain more business chances in this changing environment. The purpose of this paper is to improve service quality of international logistics companies and explores the quality function deployment in terms of quality evaluation method. The logistics service is particularly characterized by offering a series of transport solution and including other logistics activities. The major customers of the logistics services are the industrial clients. The customer satisfaction is key managerial mission since the competitiveness is a growing issue in this industry. The quality function deployment is one of the unique procedures to expose the requirements of customer and transform them into managerial tasks by cross correlation analysis between requirements and technical measures. The empirical study is performed to investigate service quality of the logistics industry by focusing on a group of leading logistics companies.
\end{abstract}

Key Words: Quality Function Deployment, Logistics Service, Quality Management.

JEL classification numbers: L80, L90, M11, M19

Submission Date: 07/10/2012 Revision Date: 06/12/2012 Acceptance Date: 23/12/2012

* Corresponding Author's Address: Sheng-Teng Huang, Department of Maritime Logistics, Kobe University, Higashinada 658-0022, Kobe, Japan. Email: m93730012@hotmail.com

** Department of Maritime Logistics, Kobe University, Kobe, Japan. Email: m93730012@hotmail.com

*** Department of Maritime Transportation and Management Engineering, Istanbul Technical University, Istanbul, Turkey. Email: duruokan@yahoo.com

**** Department of Shipping and Transportation Management, National Taiwan Ocean University, Keelung 20224, Taiwan, R.O.C. Email: m93730012@mail.ntou.edu.tw 


\section{INTRODUCTION}

The maritime transport is one of the largest service industries since around $90 \%$ of world trade is performed by seaborne transport, and the other $10 \%$ is by air or inland transport. Both Japan and Taiwan are surrounded by sea and China is also a heavily populated country with burgeoning major seaports, and international trade must be accomplished by reliable and experiential international logistics service providers (Lee, 2012). The globalization of the world economies creates many chances as well as challenges for international logistics companies to expand more business in this changing environment. More and more manufactures outsource their core logistics job to the professional logistics companies, however, a numerous of failure service cases force them to shift to better service providers with diversity of shipper's service requirement in Japan. The national logistics policy report published by Ministry of Land, Infrastructure and Tourism (2011) proposes to establish international logistics strategy teams in 10 different regions around Japan in order to satisfy the increasing demand for advance transportation infrastructure and stay competitive in Asia Pacific. In China, above a million registered logistics companies and around $90 \%$ are small or medium in size but the logistics service and infrastructure should keep pace with the consumer's demand and country's need (http://www.lloydslist.com/).

Logistics is a supply chain channel which adds the value of place and time utility. Logistics generally means a series of operational activities including inputting, packing, warehousing, information changing, transporting and physical distributing goods from point of suppliers to point of customers, and the international logistics companies can offer the firms the proper logistics solution plan and handle complicated transport task with utilizing the best transportation mode to save their logistics budget. The ISO 9001 standard stressed the importance on achieving customer satisfaction, and many studies revealed that customers will change to the service supplier whose service is perceived to have the better service quality (Hung et al., 2003). Moreover, global competition pressure forces the logistics companies to find out the way to create customer value and provide excellent service, while customer requirements are getting demanding and critical to the service providers, as a result, to satisfy the shippers' needs through hearing their voice and wants has become an important strategic and even survival issue for logistics service provider to accomplish (Mollenkopf, 2005).

To accurately express and quantify the service quality of international logistics company is difficult due to its characteristics such as intangibility, inseparability, ambiguity and heterogeneity. The perceived service quality is the interaction between service provider and customer, so the service attributes of the logistics company are practically assessed by shipper with qualitative and quantitative questionnaires. 
Nevertheless, we can find many previous researches and related studies to investigate the service quality or performance of logistics industry. Mikko (2006) investigated the mode selection criteria of Finnish logistics service. According to the research, the products with high price/kg ratio, short life cycles and worldwide market, for example in the hi-tech industries, are typical relying on rapid mode transportation due to their high time utility and worthy of expensive or speedy transport. Miyashita (2006) explained the evolution and development of logistics with life cycle theory and flying geese theory. He urged the shipping industry in Japan to combine the software and hardware in both of air and shipping transportation as the combined 3PL or 3PL mega carrier because it will ensure the long term profit stability and enjoy short term low risk. Bottani (2006) explained companies may enlarge customer satisfaction and expand market shares by improving logistics performances. He applied fuzzy QFD to empirically find out the strategic management of logistics service in an Italian company operating in the mechanical industry in terms of important warehouse functions such as IT, JT philosophy, forecasting skill, customer relationship management, order picking and warehouse lay-out optimization. Liang et al. (2008) pointed out four critical service items for an ocean freight forwarder. The four service items include operations convenience and response ability, integrated service, transportation ability, and price. Lu (2007) revealed the shippers' service attributes in logistics industry, such as documentation, storage space, transportation service, tracking system. Zhao (2007) explored the taxonomy of IT strategies utilized by 105 of 3PL companies in China with a cluster analysis survey. The study revealed the strategies can attain only IT advantages compared with their rivals but not financial or competitive advantages. Lee (2010) pointed out with the higher value of maritime logistics created, the better customer satisfaction would be attained and the key value is reflected in service effectiveness (e.g. responsiveness, flexibility and service reliability) and operational. Peter (2011) applied a two-stage DEA model to analyze the efficiency of the Brazilian 3PL for 10 years. The results of inputs and outputs analysis for each attribute are discussed to improve the scale efficiency. Chen (2012) emphasized the developing of value-added logistics activities to improve customer satisfaction. Also, the European Shipper's Council argued the port- alliance service quality of major European shipping companies and urges them to demonstrate shippers that alliance formations achieve economies of scale as well as provide better reliability and quality service. After reviewing the above journals related to measure the service quality, consulting with professor academic, experienced executive as well as shippers, we select 10 customer requirements and 11 technical measures to assess the service quality of international logistics company. 


\section{METHODOLOGY}

\subsection{The quality function deployment and house of quality}

Quality Function Deployment (QFD) was originally developed by Yoji Akao in 1966 and was intended to evaluate the particulars of products based on customer inputs. The most important tool of QFD is the House of Quality (HoQ) which was first applied in the Kobe Shipyard of Mitsubishi Heavy Industries for advancing a new building project of an oil tanker ship. Yoji Akao suggested the use of QFD for the shipbuilding industry and shortly its popularity was improved among several industries. The house of quality would be useful to allocate possible contribution of improvements into customer requirements, and the service provider can maximize customer satisfaction through execute the alternatives of improvement. This research investigates the international logistics companies and the customer requirements are discussed under the QFD method (Akao, 1989).

The procedure for building the house of quality for completion of the QFD can be constructed by the following steps:

A. Customer requirements (WHATs, CRs): Customer requirements information can be known throughout investigation or direct answers from customers. The weight of customer requirements is to identify with the level of importance and satisfaction of each item. The result of deployment stands for the voice of customers in this model. We can use the following formula to calculate the priorities of customer requirements after finding the means of importance and satisfaction rating of the surveys. Let $\overline{X i}$ and $\overline{Y i}, i=1,2, \cdots \mathrm{m}$, symbolize the average degree of importance and satisfaction to customer requirement $A i$. Because the importance degree and the priority of shipper's requirements have the direct relationship, the satisfaction degrees have the inverse relationship. We can get the priority rating $v i$ of $A i$ by $v i=(5-\overline{Y i}) \overline{X i}$.

$$
w i=\frac{v i}{\sum_{i=1}^{n} v i,}
$$

According to this formula, the standard weight $w i$ of CRs can be found.

B. Technical measures (HOWs, TMs): Technical measures are built along with a firm's service or product based the firm's resource and coordination. TMs are applicable for evaluating a firm's service or product. 
C. Relationship Matrix : Combining each WHATs and HOWs, the relationship matrix shows the contribution level and relation of each technical measure to each customer requirement. Typically, symbols represent three degree of strength (low relationship, moderate relationship, strong relationship, no relationship), such as 1-4-7 or $1-5-9$.

D. Correlation Matrix : Correlation matrix relationship is to measure the relationship of each technical measure and how much they influence each other. Correlations are represented with symbols that express the degree of relation between technical measures. Symbols are translated into a four-value rating scale (low relationship, moderate relationship, strong relationship, no relationship), such as 1-3-5-9 or $1-3-7-9$.

E. Target values: It is essential to build the relationship between customer requirements and technical measures. The crisp numeric can present the value in precision-based QFD. In practically, the business operators often estimate them according to their practical experience, skilled knowledge and information. On the other hand, the estimation of the relation power between customer requirements and technical measures is usually demonstrated in linguistic values, e.g. 'high', 'medium' and 'low'. Through calculating weight of technical measures, we can find the target values of each TM (Liang, 2008). The classical structure of the HOQ is listed in Figure 1.

The outcome of the matrix is the ranking of TMs downward order of importance. For this purpose, both the absolute and the relative importance of each TM against customer's requirements need to be calculated. In the classical QFD applications, in order to represent the relationship between $i$ th $\mathrm{CR}$ and the $j$ th $\mathrm{TM}$, the generic position $X i j$ can be used with a numeric scale. So, the absolute importance $A I j, j$ $=1, \cdots . . m$. The formula to find each $\mathrm{TM}$ is

$$
\mathrm{AI} j=\sum_{i=1}^{n} W i X i j, j=1, \cdots m
$$

$W i$ is the relative importance of the $i$ th $\mathrm{CR}, X i j$ is the numerical value put in the point $(i, j)$ of the matrix, $j=1, \cdots . . \mathrm{m}$. and $i=1, \cdots . . n$ the number of TMs and of CRs .

We can define the $R \mathrm{I} j$ through $\mathrm{AI} j$ by using the equation as follows:

$$
R \mathrm{I} j=\frac{A I j}{\sum_{j=1}^{m} A i j,} j=1, \cdots, m
$$


We can find the TMs are ranked according to $R \mathrm{I} j$ more than $\mathrm{AI} j$ through literature review. So, as the higher $R \mathrm{I} j$, the TM is more important that we should include it into the product or service for the purpose of enhancing customer satisfaction and improve the service quality (Duru et al, 2011).

\subsection{Fuzzy analytic hierarchy process}

The pair wise comparison matrix is computed with the subjective judgments of the decision makers and there might be some uncertainty associated with this judgment that is not taken into account by the analytic hierarchy process (AHP) Yang, 2004(). Therefore, Buckley 1985() proposed the evolutionary algorithm with the trapezoidal fuzzy numbers to overcome this uncertainty by using fuzzy set theory. The linguistic terms for this study are determined as in Table 1 and its fuzzy number is displayed in Figure 4. In this study, Chang's 1996() approach for FAHP is used to calculate the weight of customer satisfaction and its definition is as follows:

Definition 1: A fuzzy set $\tilde{\mathrm{A}}$ in a universe of discourse $\mathrm{R}$ is characterized by a membership function $\mu_{\tilde{A}}(x)$ which associates with each element $\mathrm{x}$ in $\mathrm{R}$ is a real number in the interval $[0,1]$. The function value $\mu_{\tilde{A}}(x)$ is termed the grade of membership of $\mathrm{x}$ in $\tilde{\mathrm{A}}$.

Definition 2: A fuzzy number is a fuzzy subset in the universe of discourse $\mathrm{R}$ that is both convex and normal.

Definition 3: A triangular fuzzy number denotes as $\tilde{A}=(1, \mathrm{~m}, \mathrm{u})$, where $1 \leq \mathrm{m}$ $\leq \mathrm{u}$, has the following triangular type membership function;

$$
\mu_{\tilde{A}}(x)=\left\{\begin{array}{cc}
0, & x<l, \\
(x-l) /(m-l), & l \leq x<m, \\
1, & x=m, \\
(u-x) /(u-m), & m<x \leq u, \\
0, & u<x .
\end{array}\right.
$$

where 1 and $\mathrm{u}$ are the lower and upper bounds of the fuzzy number $\tilde{\mathrm{A}}$, respectively, and $\mathrm{m}$ is the midpoint as shown in Figure 2.

The Chang approach for the FAHP method is stated in as follows:

Let $X=\{x 1, x 2, x 3, \cdots, x n\}$ be an object set and $U=\{u 1, u 2, \cdots, u m\}$ be a goal set. The extent analysis for each goal is performed under each object. Therefore, $\mathrm{m}$ extent analysis values for each object are indicated with the following parameters: 


$$
M_{g_{i}}^{1}, M_{g_{i}}^{2}, \ldots, M_{g_{i}}^{m}, \mathrm{i}=1,2, \cdots, \mathrm{n}
$$

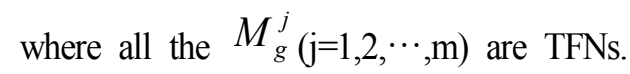

Step 1: The value of fuzzy synthetic extent with respect to the ith object is defined as

$$
S_{i}=\sum_{j=1}^{m} M_{g_{i}}^{j} \otimes\left[\sum_{i=1}^{n} \sum_{j=1}^{m} M_{g_{i}}^{j}\right]^{-1}
$$

To obtain $\sum_{j=1}^{m} M_{g_{i}}^{j}$, the fuzzy addition operation of $\mathrm{m}$ extent analysis values for a particular matrix is performed such as:

$$
\sum_{j=1}^{m} M_{g_{i}}^{j}=\left(\sum_{j=1}^{m} l_{j}, \sum_{j=1}^{m} m_{j}, \sum_{j=1}^{m} u_{j}\right)
$$

And to obtain $\left[\sum_{i=1}^{n} \sum_{j=1}^{m} M_{g_{i}}^{j}\right]^{-1}$, the fuzzy addition operation of $M_{g_{i}}^{j} \quad(\mathrm{j}=1,2, \cdots, \mathrm{m})$ values is performed such as:

$$
\sum_{i=1}^{n} \sum_{j=1}^{m} M_{g_{i}}^{j}=\left(\sum_{i=1}^{m} l_{j}, \sum_{i=1}^{m} m_{j}, \sum_{i=1}^{m} u_{j}\right)
$$

and then the inverse of the vector in Eq. (9) is computed, such as:

$$
\left[\sum_{i=1}^{n} \sum_{j=1}^{m} M_{g_{i}}^{j}\right]^{-1}=\left(\frac{1}{\sum_{i=1}^{n} u_{i}}, \frac{1}{\sum_{i=1}^{n} m_{i}}, \frac{1}{\sum_{i=1}^{n} l_{i}}\right) .
$$

Step 2: The degree of possibility of $M 2=(l 2, m 2, u 2) \geq M 1=(l 1, m 1, u 1)$ is defined as 


$$
V\left(M_{2} \geq M_{1}\right)=\sup _{y \geq x}\left\lfloor\min \left(\mu_{M_{1}}(x), \mu_{M_{2}}(y)\right)\right\rfloor
$$

and can be expressed as follows:

$$
\begin{aligned}
& V(M 2 \geq M 1)=h g t(M 1 \cap M 2) \\
& =\mu_{M_{2}}(d)=\left\{\begin{array}{c}
1, \text { if } m_{2} ? m_{1} \\
0, \text { if } l_{1} ? u_{2} \\
\frac{l_{1}-u_{2}}{\left(m_{2}-u_{2}\right)-\left(m_{1}-l_{1}\right)}, \text { otherwise. }
\end{array}\right.
\end{aligned}
$$

Figure 3 illustrates Eq. 11 where $\mathrm{d}$ is the ordinate of the highest intersection point $\mathrm{D}$ between $\mu_{M_{1}}$ and $\mu_{M_{2}}$. To compare M1 and M2, we need both the values of $V(M 1 \geq M 2)$ and $V(M 2 \geq M 1)$.

Step 3: The degree possibility for a convex fuzzy number to be greater than $k$ convex fuzzy Mi $(i=1,2, \cdots, k)$ numbers can be defined by

$$
\begin{aligned}
& V(M \geq M I, M 2, \cdots, M k)=V[(M \geq M I) \text { and }(M \geq M 2) \text { and } \cdots \text { and }(M \geq M k)] \\
& =\min V(M \geq M i), i=1,2,3, \cdots, \mathrm{k} .
\end{aligned}
$$

Assume that $d^{\prime}(A i)=\min V(S i \geq S k)$ for $k=1,2, \cdots, n ; k \neq i$. Then the weight vector is given by

$$
W^{\prime}=\left(d^{\prime}(A 1), d^{\prime}(A 2), \cdots, d^{\prime}(A n)\right) T
$$

where Ai $(i=1,2, \cdots, n)$ are $n$ elements.

Step 4: Via normalization, the normalized weight vectors are

$$
W=(d(A 1), d(A 2), \cdots, d(A n)) T,
$$

where $\mathrm{W}$ is a non-fuzzy number. 


\subsubsection{The consistency calculation for the FAHP method}

The consistency calculation for pair wise matrices plays a significant role for the FAHP method and Duru et al. (2012) proposed the centric consistency index (CCI) which is based on the geometric consistency index (GCI) Aguarón and Moreno-Jiménez, 2003Crawford and Williams, 1985(; ) is applied to compute the consistency of each matrix. The calculation of CCI is as follows:

Let $A=\left(a L_{i j}, a M_{i j}, a U_{i j}\right) n \times n$ be a fuzzy judgment matrix, and let $\mathrm{w}=$ $\left[\left(w_{L 1}, w_{M 1}, w_{U 1}\right),\left(w_{L 2}, w_{M 2}, w_{U 2}\right), \cdots,\left(w_{L n}, w_{M n}, w_{U n}\right)\right]^{T}$ be the priority vector derived from $A$ using the RGMM. The centric consistency index (CCI) is computed by

$$
\begin{aligned}
C C I(A)= & \frac{2}{(n-1)(n-2)} \sum_{i<j}\left(\log \left(\frac{a_{L i j}+a_{M i j}+a_{U i j}}{3}\right)-\log \left(\frac{w_{L i}+w_{M i}+w_{U i}}{3}\right)\right. \\
& \left.+\log \left(\frac{w_{L j}+w_{M j}+w_{U j}}{3}\right)\right)^{2}
\end{aligned}
$$

where $\mathrm{n}$ is the number of elements. When $\operatorname{CCI}(\mathrm{A})=0$, we consider $\mathrm{A}$ fully consistent. The thresholds of GCI are used for the CCI and its scale is $\overline{G C I}=0.31$ for $\mathrm{n}=3 ; \overline{G C I}=0.35$ for $\mathrm{n}=4$ and $\overline{G C I}=0.37$ for $\mathrm{n}>4$ (Aguarón et al, 2003).

\subsubsection{The prioritization of decision maker}

In the existing literature, the prioritization of each decision maker is assumed same; however, their experience and knowledge are different than each other. Duru et al. (2012) suggest that the reverse of each decision maker's consistency can be used for the weight of each matrix. The algorithm of proposed method is as follows:

Let $\mathrm{D}=\{\mathrm{d} 1, \mathrm{~d} 2, \cdots, \mathrm{dm}\}$ be the set of decision makers, and $\lambda \mathrm{k}=\{\lambda 1, \lambda 2, \cdots$, $\lambda \mathrm{m}\}$ be the weight of decision makers. The weight of decision makers $(\lambda \mathrm{k})$ is the normalized Ik for the group of experts which is calculated as follows:

$$
I_{k}=\frac{1}{C C I_{k}}
$$

where $\mathrm{Ik}$ is the inverse of the CCI,

$$
\lambda_{k}=\frac{I_{k}}{\sum_{k=1}^{m} I_{k}}
$$


where $\lambda \mathrm{k}>0, \mathrm{k}=1,2, \cdots, \mathrm{m}$, and $\sum_{k=1}^{m} \lambda_{k}=1$.

All individual matrices can be aggregated by using the aggregation of individual judgment (AIJ) or the aggregation of individual priorities (AIP) Cao et al., 2008Forman and Peniwati, 1998Ramanathan and Ganesh, 1994(; ; ). In this study, AIP is applied for the calculation of aggregation matrix because the prioritization of each decision makers is assumed different than each other and its formulation is as follows;

Let $\mathrm{A}(\mathrm{k})=\left(a_{i j}^{(k)}\right)_{n \times n}$ be the judgment matrix provided by the decision maker $\mathrm{dk}$. $w_{i}^{(k)}$ is the priority vector of criteria for each decision maker calculated by

$$
w_{i}^{(k)}=\frac{\left(\prod_{j=1}^{n} a_{i j}\right)^{1 / n}}{\sum_{i=1}^{n}\left(\prod_{j=1}^{n} a_{i j}\right)^{1 / n}}
$$

The aggregation of individual priorities is defined by

$$
w_{i}^{(w)}=\frac{\prod_{k=1}^{m}\left(w_{i}^{(k)}\right)^{\lambda_{k}}}{\sum_{i=1}^{n} \prod_{k=1}^{m}\left(w_{i}^{(k)}\right)^{\lambda_{k}}}
$$

where $w_{i}^{(w)}$ is the aggregated weight vector.

\section{THE EMPIRICAL STUDY ON LOGISTICS COMPANIES IN ASIAN REGION}

The leading logistics companies of Asian region are investigated for service quality assessment and a series of technical measures are used to convey customer requirements. A group of leading logistics companies (LLC) is compared according to technical measures and customer requirements. These companies are selected from East Asian countries such as Japan, China, South Korea and Taiwan and the name of the companies is kept confidential (alphabetical labels are used). The expert participants are professors, practitioners and experiential experts from East Asian countries. The surveys were collected by telephone, email, facsimile and personal visits.

The expert consultation is performed in two steps. In the first step, a preliminary survey is prepared to define customer needs and technical measures in a small group. 
Then, the fundamental survey is performed to collect responses for an assessment in the second step. The initial expert group considers items existing in the literature and also suggests possible novel contributions to them. At this stage, a number of customer requirements are preferred as presented in Table 2.

Several technical measures are selected to transform customer requirements to measurable and tangible indicators. Table 3 presents these technical measures for quality assessment of logistics companies. The technical measures disclose the size of logistics companies by evaluating the assets (fleet size, distribution centres, CRM centre etc.) and also expose the availability of professional organizational segments and systems. Although some of the technical measures are directly tangible items, some of them are indirectly tangible by binary selection of existence $(1 / 0)$.

The fuzzy-AHP process is applied to define the priority weights of the customer requirements. An expert group from manufacturing industry is asked to complete a pair wise comparison survey and the time spent for the business is also noted for the prioritization process. Table 4 presents the aggregated fuzzy judgment matrix for the customer requirements. CCI is 0.01 which is far less than the critical value of 0.37 . The "speedy delivery and quality" is the major requirement of the customers with relative weight of 0.26 . Since the purpose of transport is the transhipment of product in good manner, safety of cargo condition is crucial. Then, the second important variable is "cheaper service" with relative weight of 0.23 . The time spent for transport and the business reputation are following indicators among others.

The relationship matrix is the key part of HoQ in QFD assessment. A group of contributors including scholars from shipping research is asked to define correlation degree of each customer requirements with the technical measures. For this purpose, a three-level scale is used which consists of strong relationship (" $\square$ " corresponding to 9) , medium relationship (" $\boldsymbol{\Delta}$ " corresponding to 5), low relationship ("О" corresponding to 1) and no relationship ("nil" corresponding to 0 ).

Table 5 shows the final content of the matrix in two parts including the priorities of the customer requirements, the correlation matrix among the technical measures, the direction of improvement and the comparative analysis among the international logistics companies. The relative weights of the technical measures are also indicated in Table 6 .

According to the number of indications through a single row of customer requirements, "Good business reputation" is found the most dependent factor by the technical content (11 of 11 items). The "Speedy delivery and quality" (9 of 11), "Cheaper service" (8 of 11), "Excellent problem solving ability" (8 of 11) and "Strong logistics and intermodal solution" (8 of 11) are also substantially oriented by the technical measures.

The relative weights of the technical measures are calculated by using eq. $2 \& 3$. 
The particulars of operation and business developing are found the most significant improvement for the customer satisfaction. The existence of ISO 9001, particulars of customer relationship management (CRM) and supply chain integrations are considered as important indicators for the enhancement of customer satisfaction. In the right side of Table 5, the comparison of the LLC is indicated according to the customer requirements by using ranking orders. For this step of the analysis, authors endeavoured to collect responses from business practitioners of the logistics and freight forwarding industry of different countries to ensure objectivity and quality of the results.

The comparative analysis indicates that LLC $\mathrm{C}$ has superiority in general and LLC $\mathrm{A}$ and LLC D have a strong competition for the customer satisfaction. According to the logistics fees, LLC B and LLC A have the leading status among the industry. Since the cheaper service is the second important requirement, price advantage is an important parameter. LSC B is not in superior position in the remaining assessment, but its outstanding price advantage is preferable by many medium to small size industries. On the other hand, the logistic framework of the LLC C maintains several superior facilities and sophisticated business solutions which contribute to the cumulative satisfaction of the customers.

The top of the HoQ table indicates the correlation matrix of technical measures as shown in Table 6. For this reason, a four-level scale is used which consists of strong positive correlation ("++"), positive correlation ("+"), negative correlation (“-"), strong negative correlation ("--") and no correlation ("nil"). The correlation matrix is particularly useful for developing corrective actions and policies. While an industry attempts to implement a number of tasks for the improvement of the customer satisfaction according to the QFD assessment, it should be taken into consideration that the technical measures may interact and positively or negatively influence each other. Therefore, one improvement may cause unexpected loss of quality on another aspect. Although, these indications are based on a limited number of expert considerations, the implications may exist on the practical use of the results.

\section{DISCUSION ON SERVICE QUALITY IMPROVEMENT IN LSCS}

According to the research literature, a group of improvements are found critical to ensure business sustainability and increasing competitiveness in the logistics business market. A numerous of failure cases of logistics service providers lose their customers because they do not provide the right service or appropriate solutions to attain customer satisfaction in each details of service items. First of all, the customer of 
international logistics service tends to purchase a complete transport solution and expect long term relationship commitment rather one time transaction or short term cooperation. Customer cares about the transport reliability and service quality more than alliance service or other advertisement slogan stressed by logistics companies (Lee, 2011). LLCs with the strong customer relationship management have critical foremost position. In case of multimodal solution issue, customer requirement may be somehow different in terms of cost saving, delivery speed or other individual requirement. The ability of customized and individual service becomes an important task to handle according to the shipper's special requirement (Yoshida et al. 2005).

\section{CONCLUSION}

This paper investigated the service quality of international logistics companies in the Asian market and the QFD method is implemented to conduct the assessment of the services and facilities for customer satisfaction. The present study indicated the foremost requirements of the customers while transferring this information to practical improvements on technical content.

First, since the operation and business developing are found the most significant improvement for the customer satisfaction, enlarging the overall service coverage and analyzing cost performance of specific logistics functions such as order processing, transportation, warehousing will contribute to the diversified service options and decreasing the total operating cost. In February 2012, the Maersk Line CEO Thomas Knudsen identifies relative high operational cost as one of Singapore's logistics weakness compared with China, though they have high quality of labour, property and supportive government towards businesses. High operational cost may spoil the profit and competitive advantage, so it is necessary for logistics companies to analyze the costly areas such as fuel or labour to have a big savings to increase total revenue.

Second, the implement of ISO 9001will ensure the standard operation procedure and capable staff to handle every detail of logistics activity to earn the mutual trust with customers and build stronger business reputation. It is necessary for logistics companies to have more quality certificates to show their services are equal to international standard.

Third, as to the success of CRM, the logistics company should concentrate on the requirements of individual customer and conduct one-to-one marketing to their special needs. Recently, SBS Group CEO Steve Walker stresses the importance for shipper to have strong relationships and long term cooperation commitment with more than one reliable logistics or shipping service providers in 2012. Therefore, the strengthen 
functions of CRM will help logistics companies to hear the voice of their customers and build long-term cooperation agreement and commitment with their shippers to gain sustainable competitive advantage in the shipping market. Surprisingly, although the current green logistics and environmental issue catches the attention around the world, the relative weight remains the lowest and has very little contribution to customer satisfaction in this empirical study (Chang, 2006).

Finally, improving supply chain integration will directly affect the efficiency and cost of the logistics systems. The IMC Pan Asia Management's general manager of shipping and logistics reveals that China's immature internal logistics infrastructure invalidate its $60 \%$ market share of the iron ore market as world's largest iron importer. He stresses that China needs all the facilities including hardware, software, integrated supply chain systems and government policies to accommodate the increase imported iron ore. For that reason, logistics companies should provide a overall seamless supply chain systems to minimize the transit time and improve customer satisfaction. Though providing quality service is sometimes costly to many logistics companies, the further research to find out the customer's requirement is still necessary to the sustainable business and win-win relationship with customers (http://www.fairplay.co.uk). The relationship between service quality and performance can be explored for future research issue. 
Volume 10, Number 3, December 2012, pp31 54

\section{Table 1.}

Transformation for TFNs Membership Functions.

\begin{tabular}{lll}
\hline Fuzzy number & \multicolumn{1}{c}{$\begin{array}{c}\text { Linguistic scales } \\
\text { Reciprocal }\end{array}$} & Membership function \\
\hline$\tilde{A}_{1}(1,1,1)$ & Equally important & $(1,1,1)$ \\
$\tilde{A}_{2}$ & Moderately important & $(1,3,5)$ \\
$\tilde{A}_{3}^{(1 / 5,1 / 3,1)}$ & & \\
$\quad(1 / 7,1 / 5,1 / 3)$ & More important & $(3,5,7)$ \\
$\tilde{A}_{4}$ & Strongly important & $(5,7,9)$ \\
$\tilde{A}_{5}(1 / 9,1 / 7,1 / 5)$ & & \\
$(1 / 9,1 / 9,1 / 7)$ & Extremely important & $(7,9,9)$ \\
\hline
\end{tabular}

\section{Table 2.}

Customer Requirements in the Empirical Work.

\section{Customer requirements}

\section{Cheaper service}

2. Speedy delivery and quality and cargo condition
Symbol Description
CS Price of service
SDQ Time spent for delivery

GS Worldwide service and local service network

4. Efficient operation and customized ability EOC Interaction between customer and staff
5. Strong logistics and intermodal solution
SL
Ability to offer different modes of service

6. Good business reputation

GBR Public image and records of the company

7. Well information providing

WI Instant information

dynamic market situation

8. Professional sales and staff

PSS Profession and expertise of company staff

9. Excellent problem solving ability

EPS Experiential and capable to provide solution 


10. Sufficient slot supply $\quad$ SSS $\quad$ Enough capacity to large
shipment

\section{Table 3.}

Technical Measures in the Empirical Work.

1. Operation and business developing

2. IT and technical support

3. Existence of ISO $9001(1 / 0)$

4. Global network $(1 / 0)$

5. Customer relationship management

6. Human resource management

7. Performance assessment system (1/0)

8. Multimodal options

9. Strategic alliance and partnership (1/0)

10. Supply chain integration

11. Legal regulation and green logistics 
Volume 10, Number 3, December 2012, pp31 54

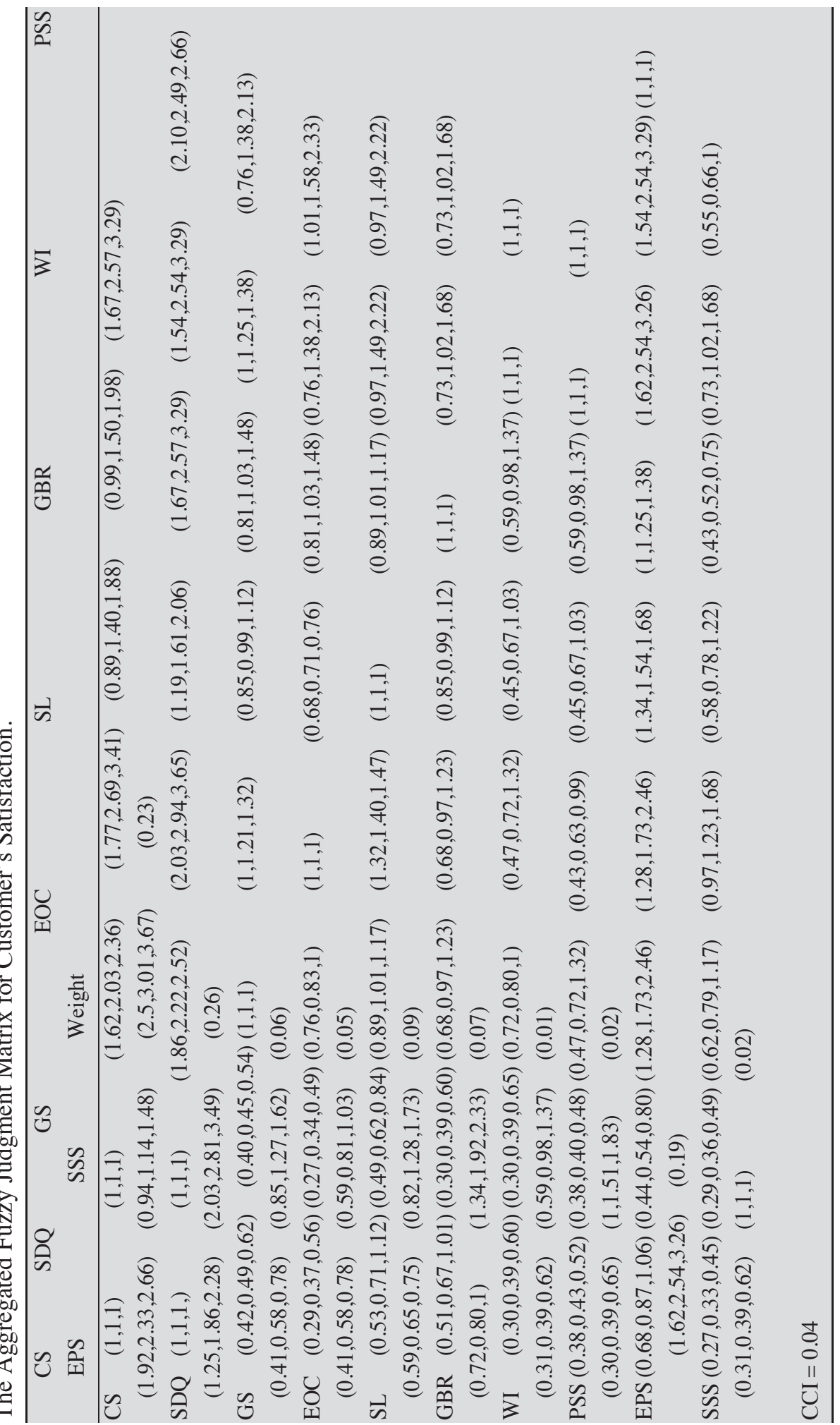




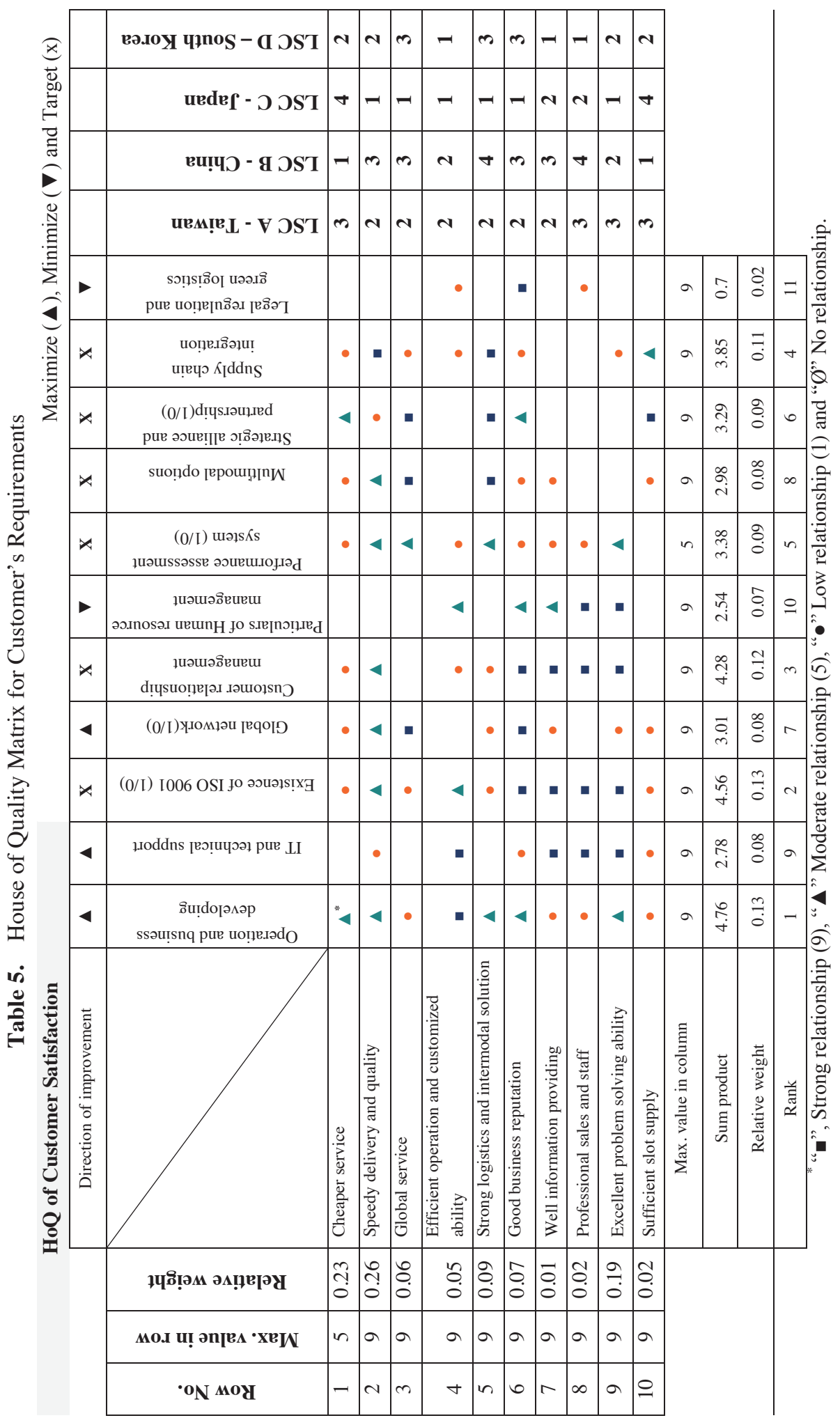


Volume 10, Number 3, December 2012, pp31 54

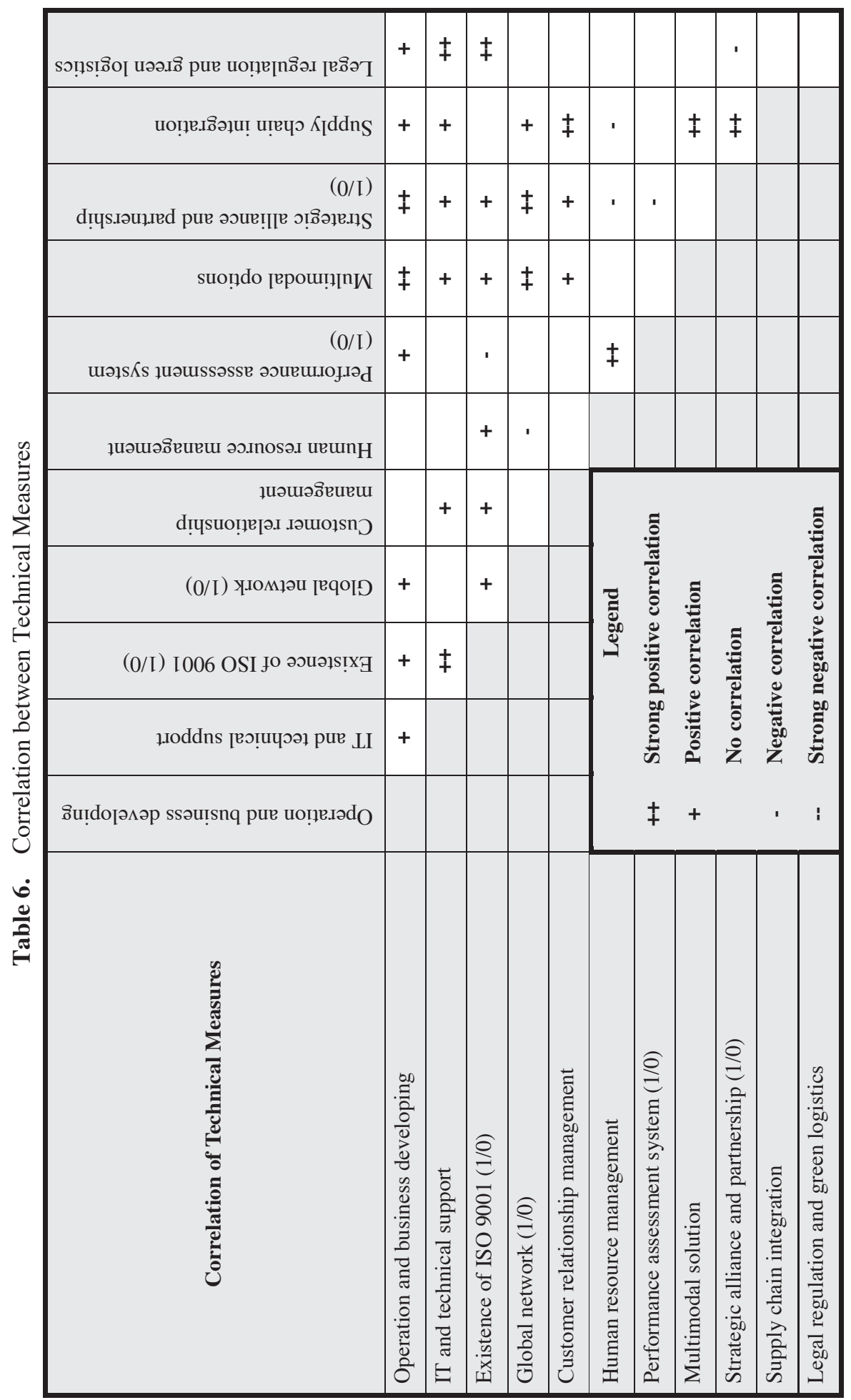




\section{Figure 1.}

House of Quality

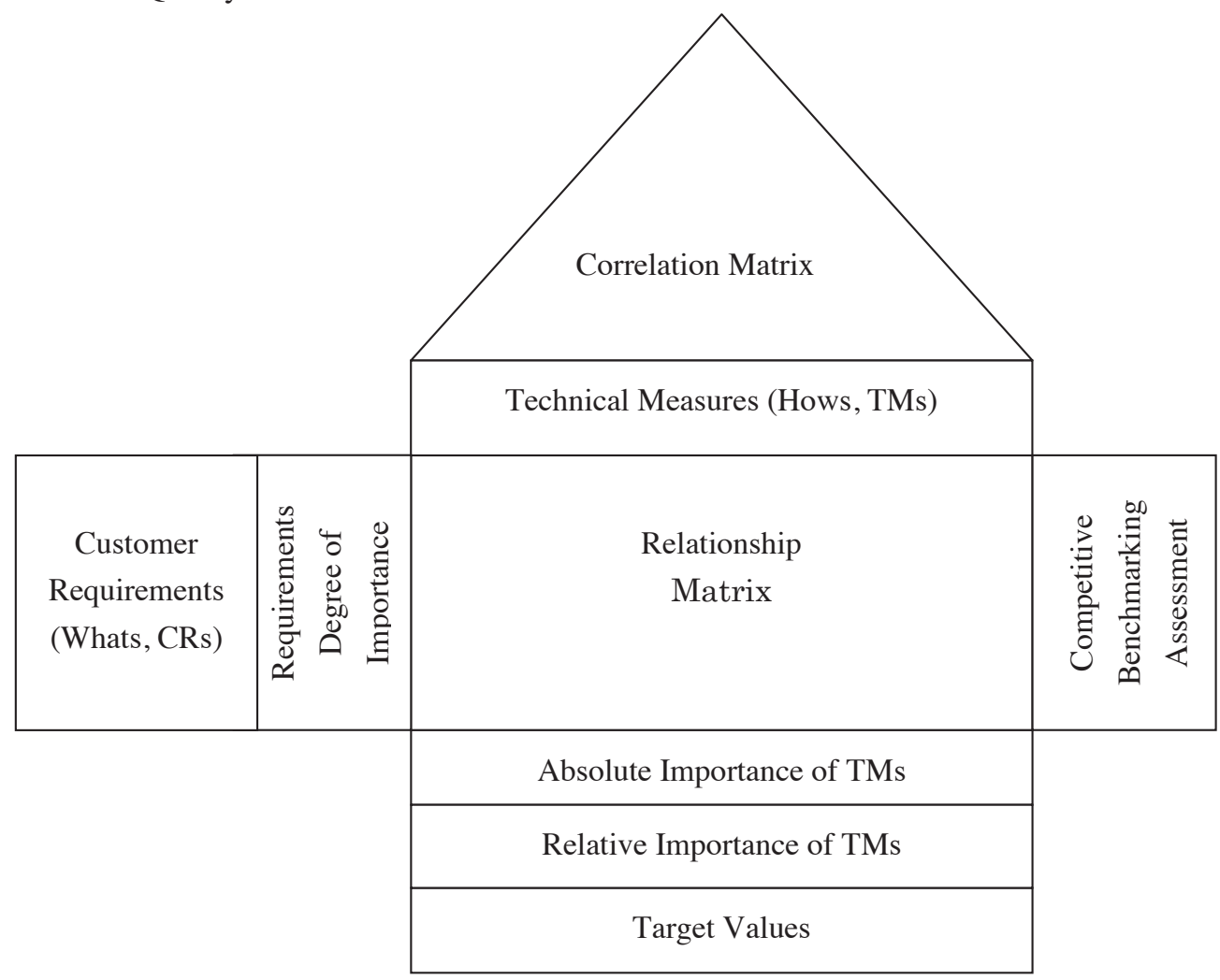

Figure 2.

A Triangular Fuzzy Number $\tilde{A}$

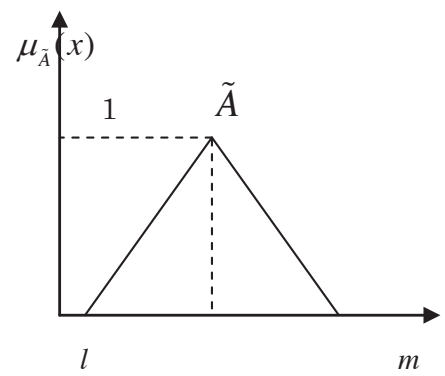


JOURNAL OF INTERNATIONAL LOGISTICS AND TRADE

Volume 10, Number 3, December 2012, pp31 54

\section{Figure 3.}

The Intersection between M1 and M2

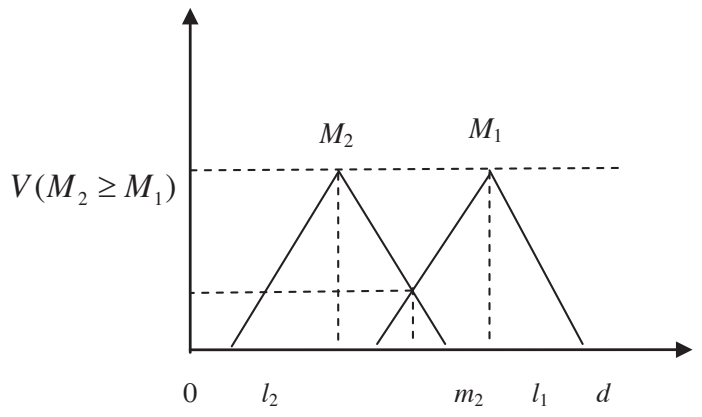

Figure 4.

Fuzzy Number of Linguistic Variable Set

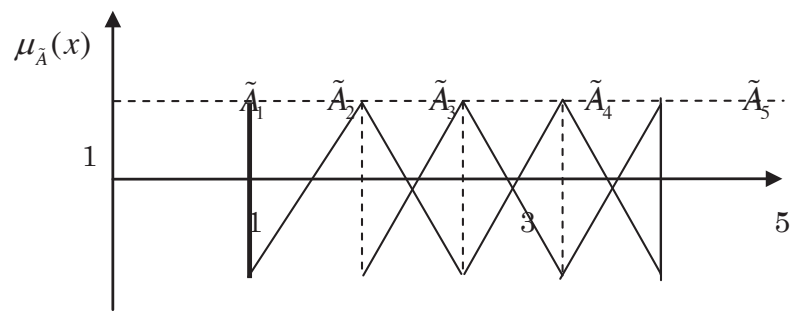




\section{ACKNOWLEDGEMENTS}

Authors are grateful to numerous business practitioners and reviewers from the transportation industry for their valuable comments and contribution to the present research.

\section{REFERENCES}

Akao, Y., Ohfuji, T.(1989) "Recent Aspects of Quality Function Deployment in Service Industries in Japan,"Conference Proceeding, Rio de Janerio, Brazil.

Aguaron, J., Moreno-Jimenez, J. M. (2003)“The Geometric Consistency Index: Approximated Thresholds,'European Journal of Operational Research, 147, 137-145.

Bottani, E., Rizzi, A.(2006)"Strategic Management of Logistics Service: A Fuzzy QFD Approach," International Journal of Production Economics ,103, 585-599.

Buckley, J. J., 1985. "Fuzzy Hierarchical Analysis,"Fuzzy Sets and Systems, 17, 233-247.

Cao, D., Leung, L. C., Law, J. S.(2008)"Modifying Inconsistent Comparison Matrix in Analytic Hierarchy Process: A Heuristic Approach,"Decision Support Systems, 44, 944-953.

Chang, D. Y.(1996)“Applications of the Extent Analysis Method on Fuzzy AHP,”. European Journal of Operational Research, 95, 649-655.

Chang, C.C., Lin K., Bao, J. Y.(2006)"Developing Direct Shipping Across the Taiwan Straits,"Marine Policy, 30, 392-399.

Chen, L., Notteboom, T.(2012)“Determinants for Assigning Value-added Logistics Services to Logistics Centres within a Supply Chain Configuration "Journal of International Logistics and Trade, 10, 3-41.

Crawford, G., Williams, C.(1985)“A Note on the Analysis of Subjective Judgment Matrices,'Journal of Mathematical Psychology, 29, 387-405.

Duru, O., Huang, S.T., Bulut, E., Yoshida, S.(2011)"Multi-layer Quality Function Deployment (QFD) Approach for Improving the Comprised Quality Satisfaction under the Agency Problem: A 3D QFD Design for the Asset Selection Problem in the Shipping Industry," Quality and Quantity, doi: 10.1007/s11135-011-9653-4.

Duru, O., Bulut, E., Yoshida, S. (2012) "Regime Switching Fuzzy AHP Model for Choice-Varying Priorities Problem and Expert Consistency Prioritization: A Cubic Fuzzy-Priority Matrix Design,” Expert Systems with Applications, 39, 4954-4964.

Forman, E., Peniwati, K.(1998)"Aggregating Individual Judgments and Priorities with the Analytic Hierarchy Process,"European Journal of Operational Research, 108, 165-169. 
Hung, Y. H., Huang, M. L., Chen, K. S.(2003)“'Service Quality Evaluation by Service Quality Performance Matrix,'Total Quality Management and Business Excellence, 14, $79-89$.

Lee, E.S., Song, D.W.(2010)“Knowledge Management for Maritime Logistics Value: Discussing Conceptual Issues,”. Maritime Policy and Management, 37, 563-583.

Lee, J.Y., Lee, M. (2011)“Comparative Analysis of Competitiveness of Logistics Companies in Korea, Japan and China," Journal of International Logistics and Trade, 9, 27-42.

Lee T. W., Lee T. C.(2012)“A New Lease Charging System for Busan Container Terminals: a Historical Case Study,"Maritime Policy and Management, 39, 91-105

Liang, G.S.(2008)“'Applying Fuzzy Quality Deployment to Identify Service Management Requirements for Customer Quality Needs,"Quality and Quantity 2010 - Springer, 44, 47-57.

Lu, C.S.(2007)"Evaluating Key Resources and Capabilities for Liner Shipping Services,"Transport Reviews, 27, 285-310.

Mikko P., Ville H.(2006)"Selection Criteria of Transportation Mode: A Case Study in Four Finnish Industry Sectors,'Transport Reviews, 26, 207-219.

MILT.(2010) Logistics Competitive Strategy, Yearbook of Ministry of Land, Infrastructure and Transportation, Tokyo, Japan, 170-180.

MILT.(2011) Policy of International and Domestic Logistics Network, Yearbook of Ministry of Land, Infrastructure and Transportation, Tokyo, Japan,130-150.

Miyashita, K.(2006) International Logistics Strategy in Global Economy, Logistics Strategy ,Tokyo, Japan.

Mollenkopf, D., Peter, G.P.(2005)"The Importance of Developing Logistics Competencies: a Study of Australian and New Zealand Firms,'International Journal of Logistics Research and Applications, 8, 1-14.

Peter F. W.(2011)“'Determinants of Scale Efficiency in the Brazilian 3PL Industry: a 10- Year Analysis,'International Journal of Production Research, 10, 548-555.

Potter, A.(2010)“Global Logistics Management ${ }^{-}{ }^{-}$Sustainability, Quality, Risks, Edited by W. Kersten, T. Blecker and H. Flamig,"International Journal of Production Research, 48, 1853-1854.

Ramanathan, R., Ganesh, L. S.(1994)“Group Preference Aggregation Methods Employed in AHP: An Evaluation and an Intrinsic Process for Deriving Members' Weight Ages,". European Journal of Operational Research, 79, 249-265.

Shams U. R.(2008) "Quality Management in Logistics Services: A comparison of Practices Between Manufacturing Companies and Logistics Firms in Australia,". Total Quality Management and Business Excellence, 19, 535-550.

Van Laarhoven, P. J. M., Pedrycz, W.(1983)“AA Fuzzy Extension of Saaty's 
Priority Theory,". Fuzzy Sets and Systems, 11, 199-227.

Yang, C. C., Chen, B.S.(2004)"Key Quality Performance Evaluation Using Fuzzy AHP,"Journal of the Chinese Institute of Industrial Engineers, 21, 543-550.

Yoshida S., Yang J. H., Kim K. H.(2005) Network Economies of Global Alliances in Liner Shipping: the Case of Japanese Liner Shipping Companies, in T.W. Lee and K. Cullinane (eds.) World Shipping and Port Development. Palgrave Macmillan, New York, 36-49.

Zadeh, L. A.(1965)“Fuzzy sets. Information and Control,"Fuzzy Set, 8, 338-353.

Zhao, F. L. X., Wang Q.(2007)“"Taxonomy of Information Technology Strategy and Its Impact on the Performance of Third-Party Logistics (3PL) in China,'International Journal of Production Research, 45, 2195-2218. 